\title{
All Blood Counts: A Manual for Blood Conservation and Patient Blood Management
}

\author{
Thomas Dafydd, John Thompson, Biddy Ridler (editors). TFM Publishing Limited, Castle \\ Hill Barns, Nr Shrewbury SY5 6LX, 2016; \$59.95 USD (\$80 CDN), 530 pages. ISBN: \\ 978-1-903378-95-3
}

Craig J. Railton, BSc, MD, PhD, FRCP(C)

Received: 6 January 2017/Revised: 24 January 2017/ Accepted: 6 February 2017/Published online: 13 February 2017

(C) Canadian Anesthesiologists' Society 2017

All Blood Counts: A Manual for Blood Conservation and Patient Blood Management is a comprehensive textbook that supports transfusion and blood bank practices. The book is understandable and covers topics in transfusion medicine in great detail with extensive referencing. ${ }^{\mathrm{A}}$ It also covers areas involved in the administration and management of blood banks and transfusion medicine, such as policy and guideline development.

The book's 30 chapters and 12 appendices cover a wide range of topics, including transfusion history, risks of transfusion with an emphasis on safety, consent, blood bank management, anesthetic and surgical techniques for blood conservation and bleeding prevention, intraoperative cell salvage, point-of-care coagulation testing, massive hemorrhage (with chapters focusing on trauma, obstetrics, gastrointestinal bleeding, and cancer), guideline development, and the future of blood transfusion. Appendices support the chapters, providing additional figures and information, with online material about transfusion.

The chapters are similarly organized. They begin with a few relevant bulleted historical and/or modern quotations, followed by background material and then a fuller discussion of the topic. The chapter finishes with conclusions, a bulleted checklist of the most important points, and extensive referencing. The language is straightforward and understandable, with figures that are clear, understandable, and effectively used.

C. J. Railton, BSc, MD, PhD, FRCP(C) ( $₫)$

Department of Anesthesia and Perioperative Medicine, Schulich

Faculty of Medicine and Dentistry, Western University, London,

ON, Canada

e-mail: Craig.Railton@lhsc.on.ca
There are several notable highlights. Readers with an interest in the history of transfusion medicine will particularly enjoy this book. In addition, Chapter 23 on thromboelastography and thromobelastometry, is one of the best explanations of these clinical tools I have ever read. In contrast, however, I was disappointed that the problem of Wrong Blood in Tube ${ }^{\mathrm{B}}$ and transfusion error prevention did not have a separate chapter, although aspects of the subject are covered in other chapters. The literature referenced in each chapter is up to date and extensive. Indeed, it would take a reader many hours of a targeted search of the literature to find the same amount of information that is found in each chapter of All Blood Counts.

Overall, this book is an easy, useful, comprehensive read. Most authors are from the United Kingdom, with a few others from the European Union. Although the focus of some chapters is somewhat Eurocentric, given the strong focus of most UK hospitals on best practice and quality assurance, the information will be useful in other countries. In particular, the acronyms used and region-specific special terminology, are well explained.

The strength of All Blood Counts is its breadth of information and the quality of presentation and referencing. It provides useful information for physicians responsible for blood transfusion, members of blood transfusion

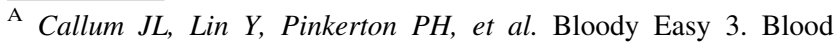
Transfusions, Blood Alternatives and Transfusion Reactions. A Guide to Transfusion Medicine, Third Edition. Ontario Regional Blood Coordinating Network; 2011

B Wrong Blood in Tube is a type of error that occurs when a crossmatch of blood is obtained and the label on the sample tube and the patient do not match. This life-threatening error can cause the wrong blood type of blood to be transfused into a patient.
} 
committees, blood bank technologists, and nurses. It will be particularly useful for anesthesia residents doing blood bank rotations and is a valuable resource for anyone involved in transfusion medicine. It should easily find a home in hospital and departmental libraries.
Conflict of interest None declared.

Editorial responsibility This submission was handled by Dr. Hilary P. Grocott, Editor-in-Chief, Canadian Journal of Anesthesia. 